\section{2cta 3 iologica Sibirica}

Journal of Biology

Founded in 2015
Altai State University

www.asu.ru

ISSN 2412-1908

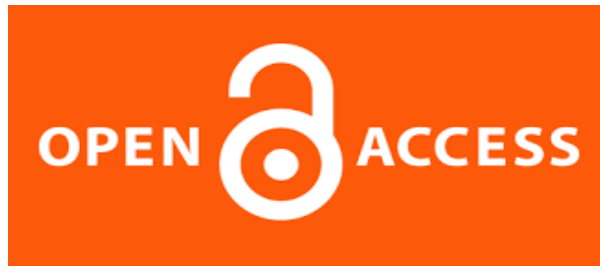

Acta Biologica Sibirica, 2017, 3(3), 111-116

\title{
Development of ecological and phytogeographical mapping in the context of the landscape approach (on the example of Altai krai)
}

\author{
I.N. Rotanova, V.V. Gaida \\ Altai State University, Barnaul, Russian Federation \\ E-mail: rotanova07@inbox.ru
}

\begin{abstract}
Modern ecological phytogeographical cartography, in its conceptual and methodological aspects, is based on theoretical and practical knowledge of vegetation, accumulated in Russia and foreign countries. There is a number of summarizing publications which thoroughly describe the peculiarities of mapped vegetation. Considerable quantities of general and specific geobotanical maps have been created to solve various scientific and applied problems. Ecological and phytogeographical maps are of paramount applied significance and are used to evaluate the quality of the environment and perspective economic use of the territories. As a rule, the creation of ecological phytogeographical maps is based on a twofold approach: traditional ecological (bioecological) and ecological-geographical. The threat to phytodiversity is a danger of vegetation transformation and conditions under which the evolution and functioning of species can aggravate or stop. The following criteria were used to design the map of vegetation degradation and the degree of threat to phytodiversity on the territory of the Altai Krai.
\end{abstract}

Key words: ecological and phytogeographical mapping; phytodiversity; landscape map; Altai Krai; vegetation cover; degradation of the vegetation cover; threat to phytodiversity

\section{Introduction}

The vegetation cover is the most dynamic component of geosystems, a vulnerable indicator of growing conditions, i.e. the ecological condition of the territory. Ecological and geographical maps of vegetation (ecological and phytogeographical maps) reflect the features of the geographical environment, consider vegetation as one of the components of geosystems (landscapes), represent changes in the vegetation cover associated with anthropogenic impact, aim at solving environmental and geographical problems of environmental quality management of the natural environment. Ecological and phytogeographical mapping is distinguished as a separate thematic area, derived from geobotanical, biogeographical, and bioecological mapping (llyina, Yurkovskaya, 1999).

The cartographic method of research, having received new potential based on the application of geoinformation technologies, is a major one in ecological and geographical studies, in particular, in assessing biodiversity and analyzing the state of the vegetation cover, using geoinformation ecological and phytogeographic mapping.

Due to significant anthropogenic impact on the nature of Altai Krai and changes in biodiversity, there is a need for ecological and geographical assessment, identification of ecological and phytogeographical problems and analysis of the nature of the environmental changes. The developed methodology with the application of the approaches of ecology and landscape mapping and geoinformation technologies made it possible to compile a series of ecological and phytogeographical maps (a map of degradation of the vegetation cover, a map of threat to phytodiversity) and to reveal changes in the vegetation cover on the territory of the region. 


\section{The main directions of ecological and phytogeographical mapping}

The vegetation cover is one of the least protected components of the landscape, which is overall exposed to human activities and suffers from it in the first place. The state of vegetation is considered to be the indicator of the level of anthropogenic load on the natural habitat (damage to stands or needles by technogenic emissions, reduction of projective coverage and productivity of pasture vegetation, etc.) and is assessed as a disturbance not only to vegetation as a component of the natural complex but also of the landscape as a whole. Botanical (geobotanical) criteria are very sensitive to environmental disturbances; they are the most representative ones ("physiognomic"), i.e. best help to trace the zones of the ecological state in terms of size in space and in stages of disruption in time (Criteria.., 1992; Rotanova, Gaida, 2016a).

V.B. Sochava singled out a special class of "environmental maps", which included all geobotanical maps, as well as other vegetation maps, which reflect its connection with human economic activity. The general ecological orientation of the entire class of environmental maps shows that they can be viewed as a single cartographic information and research system aimed at solving environmental and geographical problems of environmental quality management. This allows for more extensive use of the ecological criterion in geographical and cartographic studies, and the environmental maps themselves are defined as ecological and geographical, which corresponds to the modern use of the ecological criterion in the study of the geographical environment (Sochava, 1979).

There are three stages of application of the cartographic method in studies of vegetation (Belov et al, 2002):

1. Universal (inventory) mapping, whose task is to create vegetation maps at different scales using systems approaches to studying its spatial-dynamic organization and reflecting in the legends and on maps the basic genetic and dynamic characteristics of plant taxa;

2. Evaluation mapping, in the course of which a series of special maps are created, revealing a diverse ecological (environment-forming, landscape-protective, etc.) and resource potential of vegetation in qualitative or quantitative indicators, the degree of its anthropogenic disturbance and resistance to various types of anthropogenic impacts;

3. Forecast-advisory mapping, whose task is to develop and display vegetation maps in the future, under different natural-anthropogenic regimes and for various economic purposes of nature management. All this is expedient to carry out on the basis of the system approach to the analysis of vegetation as a component of the landscape-geographical environment and taking into account the main spontaneous and dynamic manifestations in it.

The main types of ecological and phytogeographical maps are identified by A.G. Isachenko. He divides them into six groups of maps: community types, degradation of the vegetation cover, biological contamination (introduction of weed and poisonous plants), changes in resource and environmental protection functions of vegetation, damage to vegetation, and habitat of flora (Isachenko, 2003).

Following A.G. Isachenko, during the analysis of an array of geobotanical maps, ecological-geographical maps of vegetation and those which are close to them in terms of content or plot (about 100 maps), they were subdivided into the following groups of maps: types of plant communities; degradation of the vegetation cover; dynamics of plant communities; disturbances (lesions) of plant communities (Rotanova, Gaida, 2014). For the maps of each group, differences and features of the thematic content were determined.

Maps of types of plant communities. The maps of this group unite a two-pronged approach. Mapping is carried out by plant cenoses, but within the classification units of physical and geographical differentiation of the territory. Vegetation is characterized by a complex hierarchical spatial structure (Rotanova, Gaida, 2014). This group includes: the vegetation map of the Tibetan Plateau (Arid vegetation.., 2013), the vegetation map of the Republic of Bashkortostan (Komedchikov, Lyutyy, 1995), the vegetation map of Volgograd Oblast (Komedchikov, Lyutyy, 1995), the forest cover map of Primorye (Komedchikov, Lyutyy, 1995), the coastal vegetation map of the Gulf of Finland (Volkova et al., 2001), and others. Displaying the vegetation structure is also the subject of this group of maps. An example is the forest cover map of Altai Krai (Shirokova, 1999) and the steppe vegetation map of Russia (Map.., 1990). These maps carry information on plant associations prevailing in the study areas.

Degradation maps of the vegetation cover. The maps show the changes associated with the deterioration of growing conditions, for example, with the simplification of plant cenoses caused by anthropogenic activity. There are very strong, strong, medium, weak and very weak degrees of vegetation degradation; degradation of plant communities is expressed as a percentage (Rotanova, Gaida, 2014). Examples of the maps of this group include the map of soil degradation and the vegetation cover of the limans of the Malouzenskaya system of Saratov Oblast (Tarasenko, Tuktarov, 2013), the forest degradation map of Irkutsk Oblast (Atlas.., 2004), and others.

Maps of plant community dynamics. The maps contain information on the stages of revegetation, the nature of the variability and speed of changes occurring in phytocenoses. They can be used for forecasting and scenario planning of the environmental situation. The examples are: the map of revegetation stages in the Angara river neighborhoods (Report.., 2009), the schematic map of revegetation of Nizhny Novgorod Oblast (Schematic map..,2016), the map of forest change for the 1949-1988 period in the CIS countries (Komedchikov, Lyutyy, 1995), the map of forest dynamics of Lake Baikal basin (Komedchikov, Lyutyy, 1995), revegetation map of Western Siberia after disturbances (Komedchikov, Lyutyy, 1995). 
Rotanova, I.N., Gaida, V.V. (2017). Development of ecological .... Acta Biologica Sibirica, 2017, 3(3), 111-116

Maps of plant communities disturbances (destruction). The maps show disturbances of plant cenoses caused by natural conditions or anthropogenic impact. Natural factors causing vegetation disturbance include various pests, droughts, wild fires; anthropogenic factors are deforestation, plowing, fires, caused by human fault, etc. The maps are advisory for restorative work. The examples are: the map of forest logging in the water protection zone of Lake Baikal (Komedchikov, Lyutyy, 1995), the map of forest disturbance by fires of Lake Baikal water protection zone (Komedchikov, Lyutyy, 1995), the map of vegetation disturbance in Southern Kamchatka (Komedchikov, Lyutyy, 1995), the map of vegetation damage in Moscow (Ecological atlas.., 2002).

The priority value that vegetation maps have in the system of ecological and geographical mapping is due to the fact that the vegetation cover largely determines the ecological state of a particular area, although other biogeographical maps oriented towards the solution of the ecological and geographical problems also have significant scientific and applied value (Rotanova, Gaida, 2016c).

The central place occupied by vegetation maps in the system of ecological and geographical mapping is determined by the fact that the vegetation cover largely determines the ecological state of a given territory, although other biogeographic maps that are geared to solving ecological-geographical problems (Methodological guidelines.., 1992).

The modern ecological and geographical mapping of vegetation in its conceptual and methodological constructions is based largely on the theoretical and practical experience of cartographic study of vegetation, accumulated in our country and abroad. A large number of universal and special geobotanical maps have been compiled to solve various scientific and applied problems. There are a number of generalizing publications describing features of vegetation mapping in sufficient detail (Criteria.., 1992; Kochurov et al., 2009).

\section{Ecological and phytogeographical mapping of Altai Krai}

The process of ecological and phytogeographical mapping is both methodically complicated and informatively voluminous. Cartographic interpretation of factual materials makes it possible to study not only the patterns of the landscape structure of the territory, the state of its geosystemic structured complexes, but also to identify the most important negative phenomena, to develop recommendations for optimizing nature management, and protecting the natural environment (Rotanova, Gaida, 2016c).

The territory of Altai Krai is rather densely and intensively developed, its landscapes experience significant economic burden and in many areas are significantly disturbed. In connection with the increasing anthropogenic impact on the nature of the region, there was a need for a more in-depth study of the structure and ecological state of the landscapes, and the nature of environmental changes (Rotanova et al., 1997; Rotanova et al., 2015; Rotanova, Gaida, 2016b).

Assessment of the ecological and phytogeographical problems of Altai Krai is based on the landscape approach that includes recording and studying all the main significant factors, both natural and anthropogenic, determining the state of the natural environment. The landscape approach is used in combination with the ecological and geographical approach, characterizing geosystems in terms of human activity, as well as with the cartographic method of research (Gaida, 2015a,b; Gaida, Rotanova, 2015a,b).

Geoinformation maps were compiled within the framework of works to assess the current state of the vegetation cover, including maps of the vegetation cover degradation and threats to phytodiversity. As a basic unit of the landscape study and mapping, a category of terrain is adopted that is understood as a group of territorially adjacent tracts or as a natural complex geographically arranged more complicated than a natural one but located at a taxonomic level below the landscape (Rotanova et al., 1997; Rotanova, Andreeva, 2010; Rotanova, Gaida, 2016b).

The basis for vegetation degradation mapping and the map of threats to phytodiversity was the 1: 1500000 landscape map. The map displays taxa of 111 terrain types (Rotanova, Andreeva, 2010). To represent the "restored" natural state of the vegetation cover of Altai Krai and analyze its changes over the past 100 years, the "Schematic map of the vegetation of the Altai Region with isotherms, isotheres, isocheims and isohyets", compiled in 1899 by I.P. Vydrin and Z.I. Rostovsky was used. It was published as an appendix to the "Materials on the study of soils of the Altai District" (Vydrin, Rostov, 1899). The map was digitized and served for the initial (basic) geobotanical characteristics of the territory.

The legend of the landscape map was modified in accordance with the views on the types of vegetation, set out in the works of P.N. Krylov. The following plant communities are reflected in the legend: steppes with the domination of Koeleria cristata Pers., steppes with the domination of feather grass, birch and partly aspen groves and woods; dense birch and aspen forests; pine forests; rare mixed forest (birch, aspen, fir, cedar, spruce, larch); and dense mixed forest (same species) (Rotanova et al., 2015).

The degree of detail of the ecological and phytogeographical studies corresponded to the territorial level of the geosystems studied, and was also determined by the availability of information materials. When constructing maps, the factors of anthropogenic impact were taken into account, having an area distribution and are characteristic of the region. They included land use, mainly agricultural, as well as forestry. Quantitative information on the use of nature is tied to the contours of localities for the main types of use: arable land, hayfields, pastures, and forestry. The presence of elements of residential areas, the territory of which, in general, is not reflected on the map in the scale accepted for the study. In the analysis of vegetation degradation, the following factors were considered: complete reduction of natural vegetation during plowing, its disruption in forestry development, and pasture digression. The assessment processed data on the area of arable land, pastures and forests for each locality (The main indicators.., 2012; Investment passports.., 2016; Agriculture.., 2016). All quantitative indicators used for the assessment were entered into the database. Initial information 
Rotanova, I.N., Gaida, V.V. (2017). Development of ecological .... Acta Biologica Sibirica, 2017, 3(3), 111-116

on land use included statistical reporting materials for municipalities (administrative districts) and agricultural production enterprises, averaged or maximum for the 2005-2015 period. For convenience of calculations, land use indicators were presented in the database as a percentage of the area.

The scale for the assessment of vegetation degradation was developed with the support of ecological and geographic studies and advisory-normative departmental documents previously performed for the Altai Territory. The scale has four assessment degrees in accordance with the leading criteria: 1) low degree: the area of arable land and pastures does not exceed 30\% of the area, forest cutting is not performed; 2) medium: the area of arable land and pastures does not exceed $50 \%$ of the total area, low level of pasture digression, forests are insignificant, mainly nonindustrial forest use; 3 ) high degree: the arable land does not exceed $70 \%$ of the area, digression of pastures of medium level, the presence of felling of forests over a large area; 4) very high degree: the arable land is over $70 \%$ of the area, high pasture digression and significant deforestation.

The threat to phytodiversity was assessed by a quantitative-qualitative method on the basis of the analysis of the economic use of landscapes in three stages (low, medium, high) of manifestation according to the above-mentioned criteria. The following aspects were taken into account. If over 50\% of the territory is occupied by arable land, then assessment of the threat to phytodiversity was not carried out, since there are practically no natural phytocenoses left on this territory. Hayfields were also not taken into account, as they occupy relatively small areas and are capable of rapid revegetation.

These criteria served as the basis for the construction of geoinformation maps "Vegetation degradation of Altai Krai" and "Threat of phytodiversity in Altai Krai" (fig. 1. and fig.2.). Spatial analysis showed that a very high degree of vegetation degradation is observed in $51 \%$ of the territory of the region; a high degree of degradation - in 25\%; a medium degree - in $10 \%$ and a low degree - in $13 \%$.

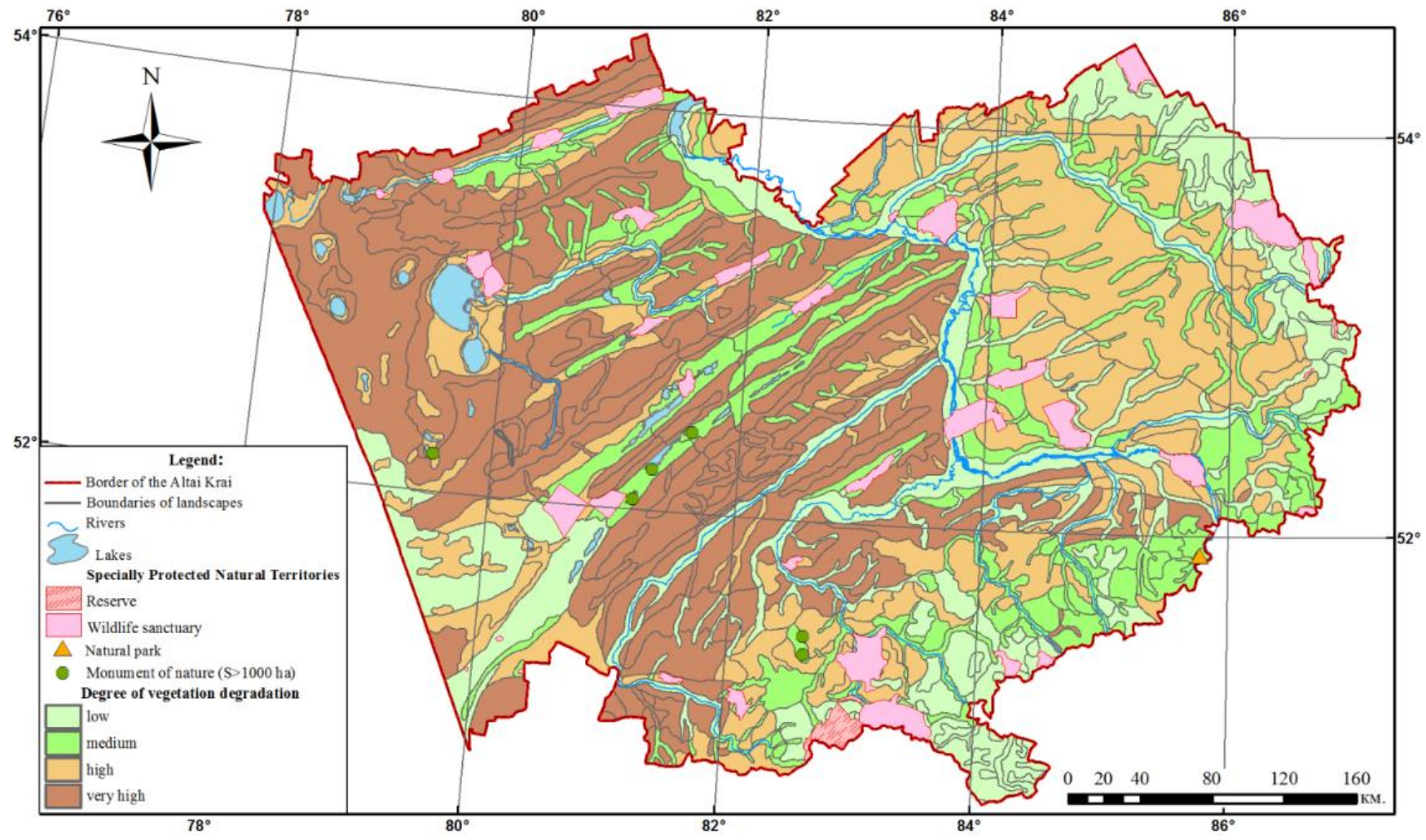

Fig. 1. Vegetation degradation of Altai Krai

Vegetation degradation is accompanied by numerous negative consequences: depletion of species composition, structure simplification, replacement of natural indigenous plant communities with synanthropic and culture derivatives, genetic diversity reduction of individual species, and fragmentation and isolation of populations. In the course of the anthropogenic transformation of the vegetation cover, with excessive burden on the site of natural-zonal plant communities, low-yield "anthropogenic waste grounds" with few species occur. In this case, revegetation seems almost impossible.

The analysis of the situation in the context of threats to phytodiversity shows that the Pre-Salair and Pre-Altay provinces are the least threatened, as well as the valleys of large rivers (Ob, Alei, Chumysh, Charysh). The medium and high levels of threats to phytodiversity are observed in the valley complexes of a number of rivers due to overgrazing of animals. Relatively preserved natural vegetation is in pine forests (medium degree of threat to phytodiversity), however, the territories exposed to fires are characterized by a high degree of threat to phytodiversity. A high degree of threat to phytodiversity is observed in the North-Western Altai and North-Altai provinces. 
Rotanova, I.N., Gaida, V.V. (2017). Development of ecological .... Acta Biologica Sibirica, 2017, 3(3), 111-116

Due to industrial forest use within the Salair Range, the degree of threat to phytodiversity in this place is increased fragmentarily to a high level. The territories of the Kulunda, South-Prialei and Upper-Ob provinces are largely plowed up (over $50 \%$ of the territory), these are zones of intensive agriculture and, accordingly, natural vegetation grows only on inconveniences.

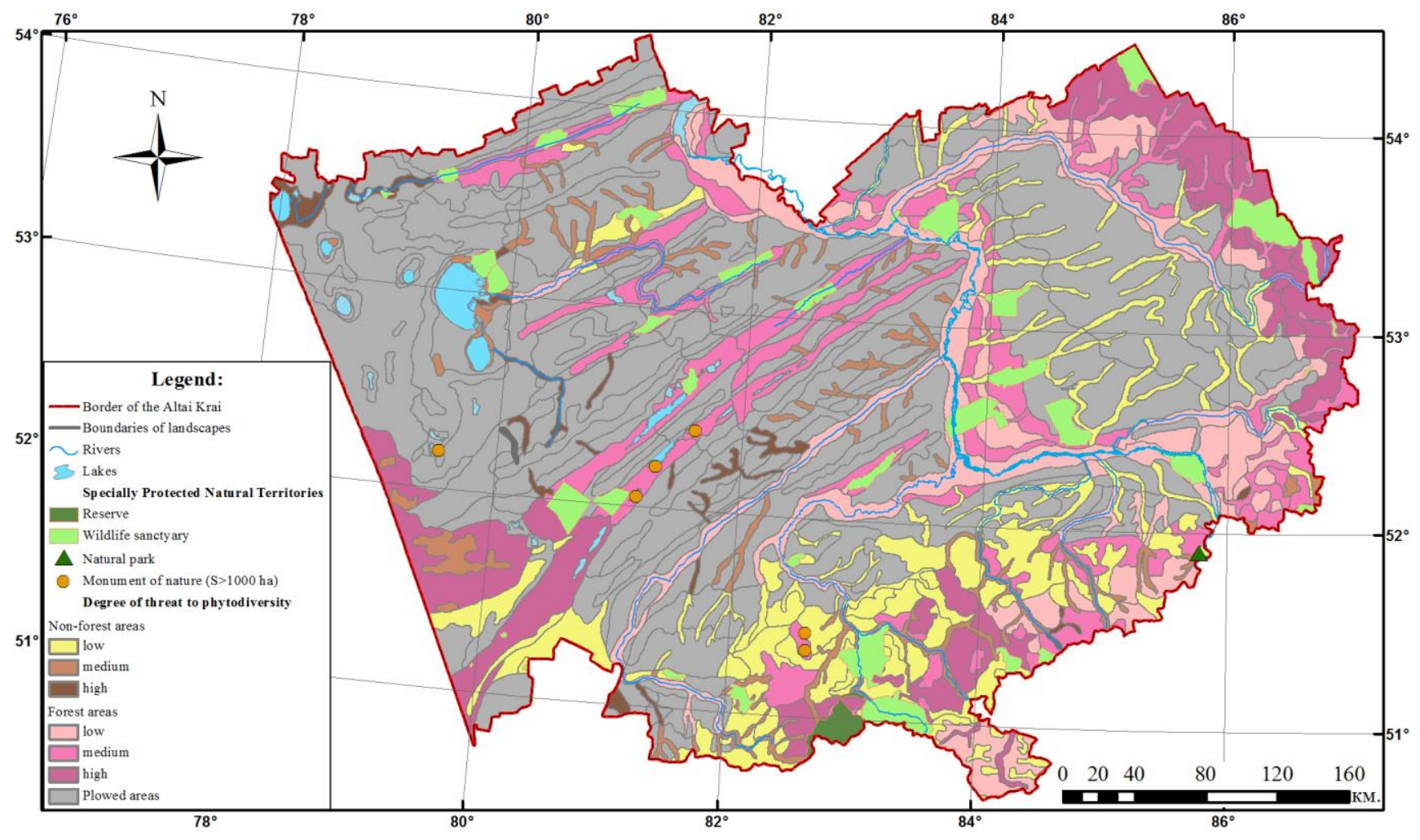

\section{Conclusion}

Fig. 2. Threat of phytodiversity in Altai Krai

Ecological and geographical vegetation maps (ecological and phytogeographical maps) display the ecological and resource potential of the territory - a set of conditions and resources of the natural environment ensuring human existence and is necessary for its economic activities. They have important applied value and are used in assessing the quality of the natural environment and the long-term economic use of the territories. The presented methodology based on the approaches of ecology-landscape mapping and geoinformation technologies allowed for creating ecological and phytogeographical maps (the vegetation degradation map and the map of threat to phytodiversity) and revealing changes in the vegetation cover in the Altai Territory over the past 100 years.

\section{References}

Agriculture, hunting and forestry. Available from: http://akstat.gks.ru/wps/wcm/connect/rosstat ts/akstat/ru/statistics/enterprises/agriculture/ Accessed on 20.09.2017

Arid vegetation of the world. Types of vegetation of the Tibetan Plateau. Available from: http://ukhtoma.ru/geobotany/asia11.htm/ Accessed on 25.08.2107

Atlas. Irkutsk region: ecological conditions of development. (2004). Moscow, Irkutsk (in Russian).

Belov, A.V., Lyamkin, V.F., Sokolova, L.P. (2002). Cartographic study of biota. Irkutsk: Oblmashinform (in Russian)

Criteria for assessing the ecological situation in the area to identify areas of environmental emergency and areas of ecological disaster (1992). Ed. N.G. Rybalsky. Moscow, The Ministry of Natural Resources of Russia (in Russian)

Ecological Atlas of Moscow. (2002). Moscow, GUP NIIPI of the General Plan of Moscow. Map of vegetation damage. Available from: http://www.ionizatory.info/health/map8.shtml/ Accessed on 25.10.2017 (in Russian).

Gaida, V.V. (2015a). Analysis of geobotanical maps for the purpose of development of geoinformation ecologicalgeographical mapping of vegetation cover (ecology-phytogeographic mapping). Ecological marathon of the XXI century: coll. materials II International. remote competition. Samara. January 31 - February 7, 2015 Samara, Publishing house "Insoma-Press" (in Russian)

Gaida, V.V. (2015b). Study of degradation of vegetation cover in the Altai Territory with the help of a cartographic method of research. Proceed. Int. Conf. "Lomonosov Readings in the Altai: Fundamental Problems of Science and Education". Barnaul, Publishing house of the Altai State University (in Russian)

Gaida, V.V., Rotanova, I.N. (2015a). Peculiarities of thematic content of ecogeographical maps of vegetation cover. Proceed. Ust-Kamenogorsk branch of the Kazakh Geogr. Society. To the 70th anniversary of the Great Victory (1941-1945). UstKamenogorsk, Shygys Polygraph (in Russian)

Gaida, V.V., Rotanova, I.N. (2015b). Estimation of threats to phytodiversity with the use of the cartographic method of investigation (on the example of the territory of the Altai Territory). Natural conditions, history and culture of Western Mongolia 
Rotanova, I.N., Gaida, V.V. (2017). Development of ecological .... Acta Biologica Sibirica, 2017, 3(3), 111-116

and adjacent regions: Materials of the XIIth International Conference. sci. Conf. Hovd, Mongolia, September 18-21, 2015, Natural Sciences, 1, Khovd-Tomsk, Publishing House of Tomsk State University (in Russian)

Ilyina, I.S., Yurkovskaya, T.K. (1999). Phytoecological mapping and its actual problems. Botanical Journal, 84(12), 1-7. (in Russian)
Investment
passports
of
municipalities.
Available
from:

http://www.econom22.ru/investment/investoram/investment passport of municipalities/ Accessed on 22.10.2017

Isachenko, A.G. (2003). Introduction to environmental geography. St. Petersburg, Publishing house of St. Petersburg State

University (in Russian)

Kochurov, B.I., Shishkina, D.Yu., Antipova, A.V., Kostovska, S.K. (2009). Geoecological mapping. B.I. Kochurov (Ed.). Moscow,

Publishing Center "Academy" (in Russian)

Komedchikov, N.N., Lyutyy, A.A. (1995). Ecology of Russia in maps: annotated bibliographic index of maps and atlases.

Moscow, TsISN Minnauky RF and RAS (in Russian)

Map of the steppe vegetation. Available from: http://oopt.info/index.php?page=195/ Accessed on 15.09.2017

Methodological guidelines for the creation of an ecological-geographical map of scale 1: 2500000 (1992). Ed. O.A. Evteev.

Moscow, Moscow State University (in Russian)

Report on the results of scientific research and scientific and organizational activities in 2009. Director. Fragment of the map of the restoration dynamics of vegetation in the Middle Angara region. Available from: http://docs.podelise.ru/docs/index8874.html/ Accessed on 11.10.2017.

Rotanova, I.N., Andreeva, I.V. (2010). Ecological and landscape substantiation of the system of specially protected natural territories of the Altai Territory. Novosibirsk, Publishing house of SB RAS (in Russian)

Rotanova, I.N., Gaida, V.V. (2014). Ecological-geographical mapping of vegetation. Development of research competences of young people in the conditions of innovative educational cluster: a collection of scientific articles of the all-Russian scientific and practical conference. Barnaul, The Publishing House of the Altai State University (in Russian)

Rotanova, I.N., Gaida, V.V. (2016a). Assessment of the disturbance of landscapes of the natural park «Foothills of the Altai». Geography and nature management of Siberia. Issue. 22. Barnaul, The Publishing House of the Altai State University (in Russian) Rotanova, I.N., Gaida, V.V. (2016b). Evaluation of Threats to Phytodiversity in the Altai Territory with the Use of Geoinformation Mapping. InterExpo GEOSibir-2016. Proceed. XII International Scientific Congress, April 20-22, 2016, Novosibirsk, 7th International Conference «Early Warning and Management in Crisis Situations in the Epoch of "Big Data", Novosibirsk

Rotanova, I.N., Gaida, V.V. (2016c). Evaluation of threats to phytodeversity by means of geoinformation cartography. Global Geospatial Information and High Resolution Global Land Cover/Land Use Mapping. Proc. of ISPRS WG IV/2 workshop, 21 April 2016, Novosibirsk, SSUGT (in Russian)

Rotanova, I.N., Purdik, L.N., Shcherbakov, A.N., Chernykh, D.V. (1997). Ecological state of landscapes of the Altai Territory (methodological approaches to assessment and mapping). Siberian Ecological Journal, 4(2), 215-229. (in Russian)

Rotanova, I.N., Silantyeva, M.M., Kurepina, N.Yu., Gaida, V.V. (2015). Studying the development of the Altai Territory on the basis of archival cartographic sources using GIS-technologies. Inform. Bull. Association «History and computer». Special Issue No. 43, September 2015. Materials of the Intern. sci. Conf. «Geoinformation systems and technologies in historical research». Barnaul, September 25-27, 2015, Barnaul, Publishing House of the Altai State University (in Russian)

Sochava, V.B. (1979). Vegetation cover on thematic maps. Novosibirsk, Nauka (in Russian)

Schematic map of the restored vegetative cover of the Nizhniy Novgorod region. Available from: http://dront.ru/old//r/\%C0\%CD\%C0\%CB\%C8\%C7/lr-analis-ris02.jpg/ Accessed on 25.09.2017

Tarasenko, P.V., Tuktarov, R.B. (2013). Modern ecological and meliorative state of engineering systems of liman irrigation of the semidesert zone of the Saratov Zavolzhye. Modern problems of science and education, 1, 427-433. (in Russian)

The main indicators of the socio-economic status of the municipal districts and urban districts of the Altai Territory. 20062011: Statistical compilation (2012). Territorial body of the Federal State Statistics Service for the Altai Territory, Barnaul (in Russian).

Shirokova, S.L. (1999). Information systems and technologies. Forests of the Altai Territory. Available from: http://www.sbras.nsc.ru/win/gis/lib/reports/97/barnaul_i.html/ Accessed on 22.08.2017

Volkova, E.A., Khromtsov, V.N., Isachenko, G.A., Bublichenko, Yu.N., Bublichenko, A.G., Makarova, M.A. (2001). Complex mapping of the natural environment of the coast of the Gulf of Finland (Luga Bay region). St. Petersburg, Publishing house of St. Petersburg State chemist-pharmacists. academy (in Russian)

Vydrin, I.P., Rostovskiy, Z.I. (1899). Materials on the study of soils of Altai Okrug: with the application of 2 maps, soil and vegetation-climatic diagrams and roses of winds. Barnaul, Typo-lithography at the Main Directorate of the Altai District (in Russian)

\section{Citation:}

Rotanova, I.N., Gaida, V.V. (2017). Development of ecological and phytogeographical mapping in the context of the landscape approach (on the example of Altai Krai). Acta Biologica Sibirica, 3 (3), 111-116.

Submitted: 22.06.2016. Accepted: 01.09.2017

cross ref http://dx.doi.org/10.14258/abs.v3i3.3622

(C) 2017 by the authors. Submitted for possible open access publication under the terms and conditions of the Creative Commons Attribution (CC BY) license (http://creativecommons.org/licenses/by/4.0/). 